\title{
Species Distribution and Antifungal Susceptibilities of Yeast Clinical Isolates from Three Hospitals in Korea, 2001 to 2007
}

\author{
Mi-Kyung Lee, M.D. ${ }^{1}$, Dongeun Yong, M.D. ${ }^{2}$, Myungsook Kim, M.T. ${ }^{2}$, Mi-Na Kim, M.D. ${ }^{3}$, and Kyungwon Lee, M.D. ${ }^{2}$ \\ Department of Laboratory Medicine', Chung-Ang University College of Medicine, Seoul; Department of Laboratory Medicine² \\ and Research Institute of Bacterial Resistance, Yonsei University College of Medicine, Seoul; Department of Laboratory Medicine ${ }^{3}$, \\ University of Ulsan College of Medicine and Asan Medical Center, Seoul, Korea
}

\begin{abstract}
Background : We utilized results from the ARTEMIS DISK Global Antifungal Surveillance Program to evaluate the species distribution and fluconazole and voriconazole susceptibilities of yeast isolates from clinical specimens in South Korea from 2001 to 2007.

Methods : Data were collected on 5,665 yeast isolates from all body sites at three locations. All investigators tested clinical yeast isolates using the CLSI M44-A disk diffusion method. Test plates were automatically read and results were recorded using the BIOMIC image analysis plate reader system (Giles Scientific, USA). Species, drug, zone diameter, susceptibility category, and quality control results were collected quarterly via e-mail for analysis.

Results: Candida albicans was the most common isolate, but a progressive increase in non- $C$. albicans Candida and noncandidal yeast species has been observed in recent years. The overall percentages of isolates in each category (susceptible, susceptible dose dependent, and resistant) were $98.8 \%, 0.5 \%$, and $0.7 \%$ and $99.2 \%, 0.2 \%$, and $0.6 \%$ for fluconazole and voriconazole, respectively. Candida of 3 species exhibited decreased susceptibility to fluconazole $(<90 \% \mathrm{~S})$ in the order of that seen with the resistant (R) species: C. krusei, C. guilliermondii, and C. glabrata. Emerging resistance to fluconazole or voriconazole was documented among isolates of Cryptococcus neoformans, Trichosporon spp., and Rhodotorula spp.

Conclusions : The species distribution and antifungal susceptibilities of yeasts may differ according to specimen type, testing method, hospital, and geographic region. Therefore, further largescaled, long-term surveillance studies are needed to isolate yeasts and to confirm the species distribution and antifungal susceptibilities of yeast isolates from clinical specimens in Korea. (Korean $J$ Lab Med 2010;30:364-72)
\end{abstract}

Key Words : Yeast, Fluconazole, Voriconazole, Surveillance

\section{서 론}

지금까지의 진균 역학과 항진균제 내성 감시는 주로 칸디다 와 Cryptococcus neoformans에 집중되어 왔으며, 흔하지 않 은 칸디다 종과 칸디다 이외의 다른 기회 감염 효모의 발생 빈

Received : January 15, 2010

Manuscript No : KJLM10-013

Revision received: May 31, 2010

Accepted : July 12, 2010

Corresponding author: Mi-Kyung Lee, M.D.

Department of Laboratory Medicine, Chung-Ang University College of Medicine, 65-207 Hangang-ro 3-ga, Yongsan-gu,

Seoul 140-757, Korea

Tel : +82-2-748-9837, Fax : +82-2-748-9929

E-mail : cpworld@cau.ac.kr

ISSN 1598-6535 C The Korean Society for Laboratory Medicine
도와 내성 양상에 관한 자료는 한시적이거나 특정 지역에 국한 되어 있는 실정이다. 국내의 경우도 항진균제 내성 감시에 관한 연구의 대부분이 특정 병원 또는 혈액에서 분리된 칸디다 종에 관한 보고였으며[1, 2], 최근 국내 다기관의 칸디다 종에 관한 항 진균제 감수성 결과에 관한 보고가 몇몇 있는 정도이다[3-6].

진균을 대상으로 하는 감시 프로그램 중에서 ARTEMIS Global Antifungal Surveillance Program (ARTEMIS Program)은 칸디다와 칸디다 이외의 효모를 포함하는 가장 크고 포괄적인 연구로 10 년 이상의 장기간 동안 40 개국의 130 개 기 관 이상에서 참여하였으며, 표준화된 항진균제 감수성 검사를 사용하여 참여한 각 병원 검사실에서 디스크확산법(일상 검사) 으로 항진균제 감수성 검사를 시행하여 그 자료를 수집하였고, 
동시에 연구를 주관하는 중앙 검사실에서 기준 검사로서의 항 진균제 검사를 병행한 대규모 연구이다[7-9]. ARTEMIS DISK Global Antifungal Surveillance (ARTEMIS DISK)의 결과는 이미 2005 년에 39 개국의 127 개 의료 기관에서 6.5 년 동안 (1997-2003년) 점막과 침습성 진균 감염 환자에서 분리된 134,715 칸디다 균주와 6,052 균주의 칸디다 이외 효모를 대상 으로 균종 분포와 fluconazole과 voriconazole에 대한 감수성 양상으로 보고된 바 있으며[7], 이어서 2007년에도 40개국의 134 개 기관에서 8.5년 동안(1997-2005년)의 ARTEMIS DISK 결과를 보고한 바 있다[8]. 국내에서도 1997년부터 현재까지 3 개 기관에서 ARTEMIS Program에 참여하고 있다.

이에 본 연구에서는 1997년 6월에서 2007년 12월까지(10.5 년) ARTEMIS Program에 참여한 41 개국의 142 개 기관에서 수집한 총 268,122 균주의 효모에 관한 자료 중에서 국내 임상 검체에서 분리된 효모의 ARTEMIS DISK 국내 결과를 분석함 으로, 국내의 다양한 임상 검체에서 분리되는 칸디다와 칸디다 이외의 효모에 관한 균종 분포와 fluconazole과 voriconazole 에 대한 감수성 양상을 보고하고자 한다.

\section{대상 및 방법}

\section{1. 대상}

2001년 1월에서 2007년 12월까지 7년 동안 ARTEMIS Program에 참여한 국내 3 개 병원의 무균 검체 및 각종 임상 검체 에서 분리되어 병원균으로 간주된[10] 총 5,665 균주의 효모를 대상으로 하였다. 정도관리를 위한 표준 균주로는 Candida albicans ATCC 90028 또는 Candida parapsilosis ATCC 22019 균주를 사용하였다. 임상 분리 균주들은 Sabouraud dextrose agar에 계대 배양하여 각 병원의 검사실 지침서에 따 라 발아관 검사, 형태학적 방법, 상품화된 동정 키트, 또는 자동 화된 동정 장비 등을 사용하여 균종 동정하였다.

\section{Fluconazole과 voriconazole 감수성 검사}

Fluconazole과 voriconazole 감수성 검사는 CLSI M44-A 에 근거하여 디스크확산법으로 시행하였으며[11], CLSI M44-A 지침이 제시되기 이전에는 Hazen 등[12]이 제시한 방법으로 시 행하였다. 배지는 $0.5 \mu \mathrm{g} / \mathrm{mL}$ 의 methylene blue와 $2 \% \mathrm{glu}-$ cose가 첨가된 Mueller-Hinton 배지를 $4 \mathrm{~mm}$ 두께로 제조하 여 사용하였다. 신선하게 제조한 Mueller-Hinton 배지에 0.5
McFarland 탁도로 맞춘 균 현탁액을 골고루 바른 후 $25 \mu \mathrm{g}$ 의 fluconazole 디스크와 $1 \mu \mathrm{g}$ 의 voriconazole 디스크(Becton Dickinson, Sparks, MD, USA)를 올려놓고 $35^{\circ} \mathrm{C}$ 에서 18-24 시간 배양 후 판독하였으며, 배양이 느린 효모는 48시간까지 배 양하여 판독하였다. 억제대 지름은 BIOMIC image analysis plate reader system (Giles Scientific, Santa Barbara, CA, $\mathrm{USA}$ )을 사용하여 판독하였다[7-9]. 정도관리의 허용 기준은 표준균주 C. albicans ATCC 90028 또는 C. parapsilosis ATCC 22019에 대한 억제대 지름이 fluconazole 디스크는 각각 28-39 $\mathrm{mm}$ 와 22-33 mm, voriconazole 디스크는 31-42 mm와 28-37 $\mathrm{mm}$ 이었으며, 7일에 1회씩 실시하였다.

판정 기준은 CLSI 기준에 따라 fluconazole의 경우 억제대 직경이 $\geq 19 \mathrm{~mm}$ 을 감수성(susceptible, $\mathrm{S}$ ), $\leq 14 \mathrm{~mm}$ 를 내성 (resistant, R), 그리고 $15 \mathrm{~mm}$ 에서 $18 \mathrm{~mm}$ 사이를 약용량 의존 감수성(susceptible dose dependent, $\mathrm{SDD}$ )으로 판정하였으며, voriconazole은 $\geq 17 \mathrm{~mm}$ 을 $\mathrm{S}, \leq 13 \mathrm{~mm}$ 를 R, $14 \mathrm{~mm}$ 에서 16 $\mathrm{mm}$ 사이를 $\mathrm{SDD}$ 로 판정하였다[11].

\section{3. 결과 분석}

디스크확산법에 의한 효모의 fluconazole과 voriconazole에 대한 감수성 결과는 BIOMIC image analysis plate reader system으로 기록한 후 분석을 위하여 Giles Scientific으로 전 자 메일을 사용하여 전송하였다. 결과에는 균주와 관련한 정보 (검체번호, 날짜, 검체종류, 환자이름, 병동분류, 병록번호), 억 제대 지름, 카테고리에 의한 감수성 결과 $(\mathrm{S}, \mathrm{SDD}$, 또는 R), 정 도관리 결과 등이 포함되며, 분석 전에 BIOMIC system에 의 하여 균주와 관련된 환자정보, 동일인에서 분리된 동일 균주 및 정도관리 결과가 벗어난 결과 등은 자동적으로 삭제되었다.

\section{결 과}

\section{1. 효모의 균종 분포}

2001년 1월에서 2007년 12 월까지 국내 3개 병원에서 총 5,665 균주의 효모가 수집되어 본 연구에 포함되었다(Table 1). 칸디 다 종이 88.2-99.7\%로 대부분을 차지하였고(평균 95.0\%), 동 정된 11종류의 칸디다 종에서 C. albicans가 가장 흔히 분리되 었으며(칸디다 종의 약 84.1\%) 2001년도에 가장 높은 빈도를 보이다가 2006년까지 지속적으로 감소하는 경향을 보였다. 이 와는 반대로 Candida glabrata, Candida tropicalis, C. parap- 
Table 1. Species distribution of Candida and other yeast isolates by year in South Korea

\begin{tabular}{|c|c|c|c|c|c|c|c|c|c|c|c|c|c|c|}
\hline \multirow{2}{*}{ Organism } & \multicolumn{2}{|c|}{2001} & \multicolumn{2}{|c|}{2002} & \multicolumn{2}{|c|}{2003} & \multicolumn{2}{|c|}{2004} & \multicolumn{2}{|c|}{2005} & \multicolumn{2}{|c|}{2006} & \multicolumn{2}{|c|}{2007} \\
\hline & $\mathrm{N}$ & $\%$ & $\mathrm{~N}$ & $\%$ & $\mathrm{~N}$ & $\%$ & $\mathrm{~N}$ & $\%$ & $\mathrm{~N}$ & $\%$ & $\mathrm{~N}$ & $\%$ & $\mathrm{~N}$ & $\%$ \\
\hline \multicolumn{15}{|l|}{ Candida spp. } \\
\hline C. albicans & 426 & 93.42 & 588 & 89.36 & 914 & 86.64 & 687 & 81.40 & 473 & 70.28 & 766 & 68.09 & 671 & 78.60 \\
\hline C. glabrata & 5 & 1.10 & 15 & 2.28 & 29 & 2.75 & 39 & 4.62 & 41 & 6.09 & 48 & 4.27 & 40 & 4.70 \\
\hline C. tropicalis & 8 & 1.75 & 26 & 3.95 & 38 & 3.60 & 36 & 4.27 & 49 & 7.28 & 81 & 7.20 & 33 & 3.90 \\
\hline C. parapsilosis & 8 & 1.75 & 22 & 3.34 & 57 & 5.40 & 58 & 6.87 & 41 & 6.09 & 74 & 6.58 & 40 & 4.70 \\
\hline C. guilliermondii & 1 & 0.22 & & & 6 & 0.57 & 2 & 0.24 & 2 & 0.30 & 7 & 0.62 & 2 & 0.20 \\
\hline C. krusei & & & 2 & 0.30 & 3 & 0.28 & 2 & 0.24 & 4 & 0.59 & 7 & 0.62 & 1 & 0.10 \\
\hline C. Iusitaniae & & & & & & & 3 & 0.36 & 2 & 0.30 & 3 & 0.27 & 3 & 0.40 \\
\hline C. pelliculosa & & & 1 & 0.15 & 2 & 0.19 & 2 & 0.24 & 4 & 0.59 & & & & \\
\hline C. famata & 2 & 0.44 & & & & & & & & & & & 1 & 0.10 \\
\hline C. dubliniensis & & & & & & & & & & & 2 & 0.18 & & \\
\hline C. haemulonii & & & & & & & & & & & 1 & 0.09 & & \\
\hline Other Candida spp. & & & 2 & 0.30 & & & & & & & 3 & 0.27 & & \\
\hline C. neoformans & & & & & 1 & 0.09 & 3 & 0.36 & 17 & 2.53 & 10 & 0.89 & 4 & 0.50 \\
\hline \multicolumn{15}{|l|}{ Trichosporon spp. } \\
\hline T. beigelii/cutaneum & 6 & 1.32 & 1 & 0.15 & & & & & 2 & 0.30 & 3 & 0.27 & & \\
\hline T. asahii & & & & & & & 1 & 0.12 & & & 1 & 0.09 & 1 & 0.10 \\
\hline T. inkin & & & & & & & & & & & 1 & 0.09 & & \\
\hline T. mucoides & & & & & & & & & & & 1 & 0.09 & & \\
\hline Other Trichosporon sp & & & & & & & 5 & 0.59 & & & 2 & 0.18 & 2 & 0.20 \\
\hline Rhodotorula spp. & & & & & & & 1 & 0.12 & 1 & 0.15 & 1 & 0.09 & & \\
\hline Saccharomyces spp. & & & & & & & 1 & 0.12 & & & 3 & 0.27 & & \\
\hline Pichia spp. & & & & & & & & & 1 & 0.15 & 6 & 0.53 & & \\
\hline Other yeasts & & & 1 & 0.15 & 5 & 0.47 & 4 & 0.47 & 36 & 5.35 & 105 & 9.33 & 56 & 6.60 \\
\hline Total & 456 & & 658 & & 1,055 & & 844 & & 673 & & 1,125 & & 854 & \\
\hline
\end{tabular}

Includes all specimen types and all locations in the hospitals of 3 institutions.

Abbreviations: \%, \% of total isolates tested; spp., species; $C$. neoformans, Cryptococcus neoformans.

silosis는 2001년도에 가장 낮은 빈도를 보였고 그 이후 지속적 으로 증가하였다.

본 연구에서 칸디다 이외의 효모가 총 282균주(전체의 5.0\%) 분리되었고 이 중 $73.4 \%$ (207/282균주)가 동정되지 않은 기타 효모로 보고되었으며, 동정된 균 중에서는 C. neoformans (35 균주)와 Trichosporon spp. (26균주)의 순으로 많이 분리되었 다(Table 1).

\section{2. 효모의 fluconazole과 voriconazole 감수성}

2001년부터 2007년 사이에 국내 3개 병원의 임상 검체에서 분리된 효모를 대상으로 CLSI에 근거한 디스크확산법으로 시 행한 fluconazole과 voriconazole에 대한 감수성 결과와 억제 대 지름의 분포에 관한 자료는 Table 2 와 Fig. 1 에 각각 정리하 였다. 효모의 fluconazole과 voriconazole에 대한 감수성 결과 는 각각 감수성률이 $98.8 \%(\mathrm{~S}), 0.5 \%(\mathrm{SDD}), 0.7 \%(\mathrm{R})$ 와 $99.2 \%$ (S), $0.2 \%(\mathrm{SDD}), 0.6 \%(\mathrm{R})$ 였으며, 전체적으로 fluconazole에 비하여 voriconazole에 대한 감수성률이 높았다.
칸디다 종에서 fluconazole에 $90 \%$ 이상의 균주가 감수성인 균종은 C. albicans (99.7\%), C. parapsilosis (99.7\%), C. tropicalis (99.6\%)와 기타 분리빈도가 낮은 균종들이었으며(100\%), 감수성이 감소된 균종( $90 \%$ 미만의 균주가 감수성)은 Candida krusei (31.6\%), Candida guilliermondii (80.0\%)와 C. glabrata (89.4\%)로 나타났다. Voriconazole에 대한 칸디다 종의 감수성 결과도 fluconazole과 유사한 양상을 보여주고 있지만, C. krusei $(77.8 \%)$ 를 제외하고는 모든 칸디다 종의 $90 \%$ 이상이 감수 성이었다.

칸디다 이외의 효모에서는 fluconazole에 $90 \%$ 이상의 균주 가 감수성인 균종은 C. neoformans (97.1\%), Trichosporon asahii (100\%), Trichosporon inkin (100\%), Saccharomyces spp. (100\%), Pichia spp. (100\%), 기타 효모균(98.6\%) 등이었 으며, 감수성이 감소된 균종 $(90 \%$ 미만의 균주가 감수성)은 Trichosporon mucoides (0\%), Rhodotorula spp. (0\%), Trichosporon spp. (77.8\%), Trichosporon beigelii/cutaneum (83.3\%)로 나타났다. Voriconazole에 대한 감수성 결과도 fluconazole과 유사한 양상을 보여주고 있지만, T. mucoides 
Table 2. In vitro susceptibilities of yeast isolates to fluconazole and voriconazole, 2001 to 2007

\begin{tabular}{|c|c|c|c|c|c|c|c|c|}
\hline \multirow{2}{*}{ Organism } & \multicolumn{4}{|c|}{ Fluconazole } & \multicolumn{4}{|c|}{ Voriconazole } \\
\hline & $\mathrm{N}$ & $\% \mathrm{~S}$ & $\%$ SDD & $\% R$ & $\mathrm{~N}$ & $\% \mathrm{~S}$ & $\% S D D$ & $\% R$ \\
\hline \multicolumn{9}{|l|}{ Candida spp. } \\
\hline C. albicans & 4,525 & 99.7 & 0.1 & 0.2 & 4,393 & 99.7 & & 0.3 \\
\hline C. glabrata & 217 & 89.4 & 5.1 & 5.5 & 212 & 91.5 & 3.3 & 5.2 \\
\hline C. tropicalis & 271 & 99.6 & & 0.4 & 268 & 98.1 & 0.7 & 1.1 \\
\hline C. parapsilosis & 300 & 99.7 & 0.3 & & 296 & 99.7 & & 0.3 \\
\hline C. guilliermondii & 20 & 80.0 & 15.0 & 5.0 & 20 & 95.0 & & 5.0 \\
\hline C. krusei & 19 & 31.6 & 15.8 & 52.6 & 18 & 77.8 & 11.1 & 11.1 \\
\hline C. Iusitaniae & 11 & 100 & & & 11 & 100 & & \\
\hline C. pelliculosa & 9 & 100 & & & 9 & 100 & & \\
\hline C. famata & 3 & 100 & & & 2 & 100 & & \\
\hline C. dubliniensis & 2 & 100 & & & 2 & 100 & & \\
\hline C. haemulonii & 1 & 100 & & & 1 & 100 & & \\
\hline Other Candida spp. & 5 & 100 & & & 5 & 100 & & \\
\hline C. neoformans & 35 & 97.1 & 2.9 & & 36 & 97.2 & & 2.8 \\
\hline \multicolumn{9}{|l|}{ Trichosporon spp. } \\
\hline T. beigeliilcutaneum & 12 & 83.3 & 8.3 & 8.3 & 12 & 100 & & \\
\hline T. asahii & 3 & 100 & & & 3 & 100 & & \\
\hline T. inkin & 1 & 100 & & & 1 & 100 & & \\
\hline T. mucoides & 1 & & 100 & & 1 & & 100 & \\
\hline Other Trichosporon spp. & 9 & 77.8 & & 22.2 & 9 & 100 & & \\
\hline Rhodotorula spp. & 3 & & & 100 & 3 & 33.3 & & 66.7 \\
\hline Saccharomyces spp. & 4 & 100 & & & 4 & 100 & & \\
\hline Pichia spp. & 7 & 100 & & & 7 & 100 & & \\
\hline Other yeasts & 207 & 98.6 & & 1.4 & 207 & 100 & & \\
\hline Total & 5,665 & 98.8 & 0.5 & 0.7 & 5,520 & 99.2 & 0.2 & 0.6 \\
\hline
\end{tabular}

Includes all specimen types and all locations in the hospitals of 3 institutions.

Abbreviations: S, susceptible; SDD, susceptible dose dependent; R, resistant; C. neoformans, Cryptococcus neoformans; spp., species.
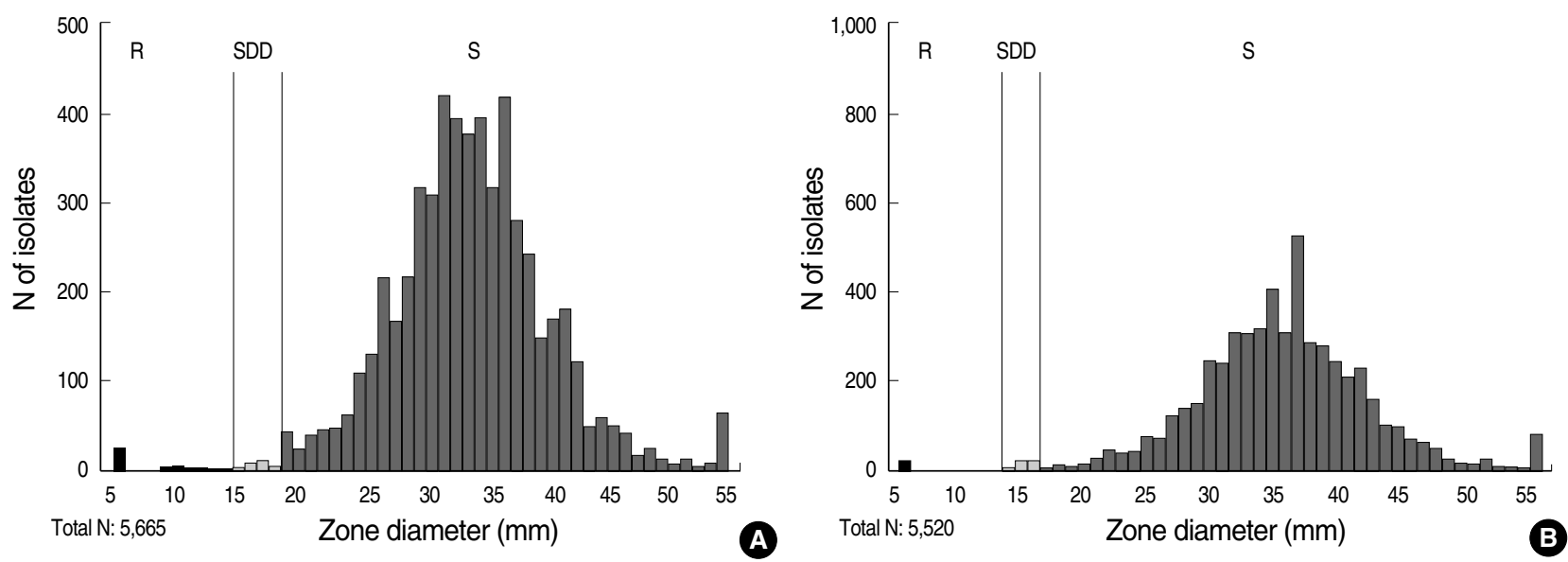

Fig. 1. Fluconazole $(A)$ and voriconazole $(B)$ zone diameter $(\mathrm{mm})$ distribution of all yeast isolates.

Abbreviations: S, susceptible; SDD, susceptible dose dependent; R, resistant.

(0\%)와 Rhodotorula spp. (33.3\%)를 제외하고는 $90 \%$ 이상이 감수성이었다.

\section{3. 효모의 fluconazole과 voriconazole 내성률 추세}

2001년 1월에서 2007년 12월까지 7년간 국내 임상 분리 효
모의 fluconazole에 대한 내성률은 전체적으로 $0.2-1.6 \%$ 로 조 사되었고, 일관된 감소나 증가 추세를 보이지는 않았으며 2005 년에 가장 높은 내성률을 보였다(Table 3). 칸디다 종에서 fluconazole 내성균이 있는 균종은 C. krusei (R, 0-100\%), C. glabrata (R, 0-17.2\%), C. guilliermondii (R, 0-14.3\%), C. albicans (R, 0-0.8\%)였고, 그 외의 칸디다 종은 전체 조사기 
Table 3. Trends in resistance to fluconazole among yeast isolates as determined by the CLSI disk diffusion method over a 7-yr period

\begin{tabular}{|c|c|c|c|c|c|c|c|c|c|c|c|c|c|c|}
\hline \multirow{2}{*}{ Organism } & \multicolumn{2}{|c|}{2001} & \multicolumn{2}{|c|}{2002} & \multicolumn{2}{|c|}{2003} & \multicolumn{2}{|c|}{2004} & \multicolumn{2}{|c|}{2005} & \multicolumn{2}{|c|}{2006} & \multicolumn{2}{|c|}{2007} \\
\hline & $\mathrm{N}$ & $\%$ & $\mathrm{~N}$ & $\%$ & $\mathrm{~N}$ & $\%$ & $N$ & $\%$ & $\mathrm{~N}$ & $\%$ & $N$ & $\%$ & $\mathrm{~N}$ & $\%$ \\
\hline \multicolumn{15}{|l|}{ Candida spp. } \\
\hline C. albicans & 426 & 0.0 & 588 & 0.3 & 914 & 0.1 & 687 & 0.3 & 473 & 0.8 & 766 & 0.0 & 671 & 0.0 \\
\hline C. glabrata & 5 & 0.0 & 15 & 6.7 & 29 & 17.2 & 39 & 2.6 & 41 & 4.9 & 48 & 6.3 & 40 & 0.0 \\
\hline C. tropicalis & 8 & 0.0 & 26 & 0.0 & 38 & 2.6 & 36 & 0.0 & 49 & 0.0 & 81 & 0.0 & 33 & 0.0 \\
\hline C. parapsilosis & 8 & 0.0 & 22 & 0.0 & 57 & 0.0 & 58 & 0.0 & 41 & 0.0 & 74 & 0.0 & 40 & 0.0 \\
\hline C. guilliermondii & 1 & 0.0 & & & 6 & 0.0 & 2 & 0.0 & 2 & 0.0 & 7 & 14.3 & 2 & 0.0 \\
\hline C. krusei & & & 2 & 50.0 & 3 & 33.3 & 2 & 0.0 & & 00.0 & 7 & 42.9 & 1 & 100.0 \\
\hline C. Iusitaniae & & & & & & & 3 & 0.0 & 2 & 0.0 & 3 & 0.0 & 3 & 0.0 \\
\hline C. pelliculosa & & & 1 & 0.0 & 2 & 0.0 & 2 & 0.0 & 4 & 0.0 & & & & \\
\hline C. famata & 2 & 0.0 & & & & & & & & & & & 1 & 0.0 \\
\hline C. dubliniensis & & & & & & & & & & & 2 & 0.0 & & \\
\hline C. haemulonii & & & & & & & & & & & 1 & 0.0 & & \\
\hline Other Candida spp. & & & 2 & 0.0 & & & & & & & 3 & 0.0 & & \\
\hline C. neoformans & & & & & 1 & 0.0 & 3 & 0.0 & 17 & 0.0 & 10 & 0.0 & 4 & 0.0 \\
\hline \multicolumn{15}{|l|}{ Trichosporon spp. } \\
\hline T. beigelii/cutaneum & 6 & 16.7 & 1 & 0.0 & & & & & 2 & 0.0 & 3 & 0.0 & & \\
\hline T. asahii & & & & & & & 1 & 0.0 & & & 1 & 0.0 & 1 & 0.0 \\
\hline T. inkin & & & & & & & & & & & 1 & 0.0 & & \\
\hline T. mucoides & & & & & & & & & & & 1 & 0.0 & & \\
\hline Other Trichosporon sp & & & & & & & 5 & 20.0 & & & 2 & 50.0 & 2 & 0.0 \\
\hline Rhodotorula spp. & & & & & & & 1 & 100.0 & & 00.0 & & 100.0 & & \\
\hline Saccharomyces spp. & & & & & & & 1 & 0.0 & & & 3 & 0.0 & & \\
\hline Pichia spp. & & & & & & & & & 1 & 0.0 & 6 & 0.0 & & \\
\hline Other yeasts & & & 1 & 0.0 & 5 & 0.0 & 4 & 0.0 & 36 & 0.0 & 105 & 1.0 & 56 & 3.6 \\
\hline Total & 456 & 0.22 & 658 & 0.61 & 1,055 & 0.76 & 844 & 0.59 & 673 & 1.6 & 1,125 & 0.9 & 854 & 0.4 \\
\hline
\end{tabular}

Includes all specimen types and all locations in the hospitals of 3 institutions.

Abbreviations: R, resistant; spp., species; $C$. neoformans, Cryptococcus neoformans.

간 동안 모두 감수성이었다. C. albicans의 경우 2002년에서 2005년 사이에 내성균이 검출되었으나, 2006년과 2007년에는 본 연구에 수집된 균에서의 내성균은 없었다. 칸디다 이외의 효 모에서는 대부분 fluconazole에 감수성이었으며, 내성균은 Trichosporon spp. (R, 0-50\%), Rhodotorula spp. (R, 100\%), 동정되지 않은 효모(R, 0-3.6\%)에서 검출되었다.

2001년부터 2007년까지 7년간 voriconazole에 대한 국내 임상 분리 효모의 내성률은 전체적으로 $0.1-1.6 \%$ 로 조사되었 으며, fluconazole의 경우와 마찬가지로 일관된 감소나 증가 추 세를 보이지 않으면서 2005년에 내성률이 가장 높았다(Table 4). 칸디다 종에서 voriconazole 내성균이 있는 균종은 C. krusei (R, 0-100\%), C. glabrata (R, 0-20.7\%), C. guilliermondii (R, 0-14.3\%), C. tropicalis (R, 0-5.3\%), C. parapsilosis (R, 0-1.7\%), C. albicans (R, 0-1.3\%)였고, 그 외의 칸디다 종 은 모두 감수성이었다. C. albicans의 경우 2004년, 2006년 및 2007 년에는 내성균이 없었다. 칸디다 이외의 효모에서는 대부분 voriconazole에 감수성이었으며, 내성균은 C. neoformans (R, 0-5.9\%)와 Rhodotorula spp. (R, 0-100\%)에서 검출되었다.

\section{4. 검체 별 효모의 fluconazole과 voriconazole 감수성}

효모가 분리된 검체는 요로(18.4\%), 호흡기(17.2\%), 혈액 (11.8\%), 기타 체액(4.4\%), 피부와 연조직(2.8\%), 생식기 검체 (1.8\%)의 순으로 많았으며, 매우 드문 검체와 검체 유형이 기록 되지 않은 경우는 "기타(miscellaneous/other)"로 분류하였다 (Table 5).

Fluconazole에 대한 내성률은 하부 위장관 검체(8.1\%), 상기 도 검체(3.1\%), 혈액(2.0\%)의 순으로 높았으며, voriconazole 대한 내성률은 뇌척수액(5.7\%), 하부 위장관 검체(2.8\%), 혈액 (1.7\%), 상기도 검체 $(1.5 \%)$ 의 순으로 높았다.

\section{고 찰}

혈액을 포함한 각종 임상 검체에서 분리된 효모에서 칸디다 종의 분리 비율은, 1997년에서 2005년까지 7.5년간 ARTEMIS Program 전체에서 수집된 결과가 95.2-96.3\%로 거의 변화가 없는데 비하여[8] 2001년에서 2007년까지 7년간 국내에서 분리 
Table 4. Trends in resistance to voriconazole among yeast isolates as determined by the CLSI disk diffusion method over a 7-yr period

\begin{tabular}{|c|c|c|c|c|c|c|c|c|c|c|c|c|c|c|}
\hline \multirow{2}{*}{ Organism } & \multicolumn{2}{|c|}{2001} & \multicolumn{2}{|c|}{2002} & \multicolumn{2}{|c|}{2003} & \multicolumn{2}{|c|}{2004} & \multicolumn{2}{|c|}{2005} & \multicolumn{2}{|c|}{2006} & \multicolumn{2}{|c|}{2007} \\
\hline & $\mathrm{N}$ & $\%$ & $\mathrm{~N}$ & $\%$ & $\mathrm{~N}$ & $\%$ & $\mathrm{~N}$ & $\%$ & $N$ & $\%$ & $\mathrm{~N}$ & $\%$ & $\mathrm{~N}$ & $\%$ \\
\hline \multicolumn{15}{|l|}{ Candida spp. } \\
\hline C. albicans & 347 & 0.3 & 588 & 0.5 & 913 & 0.1 & 687 & 0.0 & 473 & 1.3 & 766 & 0.0 & 619 & 0.0 \\
\hline C. glabrata & 3 & 0.0 & 15 & 0.0 & 29 & 20.7 & 39 & 0.0 & 41 & 2.4 & 48 & 6.3 & 37 & 2.7 \\
\hline C. tropicalis & 8 & 0.0 & 26 & 0.0 & 38 & 5.3 & 36 & 0.0 & 49 & 2.0 & 81 & 0.0 & 30 & 0.0 \\
\hline C. parapsilosis & 7 & 0.0 & 22 & 0.0 & 57 & 0.0 & 58 & 1.7 & 41 & 0.0 & 74 & 0.0 & 37 & 0.0 \\
\hline C. guilliermondii & 1 & 0.0 & & & 6 & 0.0 & 2 & 0.0 & 2 & 0.0 & 7 & 14.3 & 2 & 0.0 \\
\hline C. krusei & & & 1 & 0.0 & 3 & 0.0 & 2 & 0.0 & 4 & 25.0 & 7 & 0.0 & 1 & 100.0 \\
\hline C. Iusitaniae & & & & & & & 3 & 0.0 & 2 & 0.0 & 3 & 0.0 & 3 & 0.0 \\
\hline C. pelliculosa & & & 1 & 0.0 & 2 & 0.0 & 2 & 0.0 & 4 & 0.0 & & & & \\
\hline C. famata & 1 & 0.0 & & & & & & & & & & & 1 & 0.0 \\
\hline C. dubliniensis & & & & & & & & & & & 2 & 0.0 & & \\
\hline C. haemulonii & & & & & & & & & & & 1 & 0.0 & & \\
\hline Other Candida spp. & & & 2 & 0.0 & & & & & & & 3 & 0.0 & & \\
\hline C. neoformans & & & & & 1 & 0.0 & 3 & 0.0 & 17 & 5.9 & 11 & 0.0 & 4 & 0.0 \\
\hline \multicolumn{15}{|l|}{ Trichosporon spp. } \\
\hline T. beigelii/cutaneum & 6 & 0.0 & 1 & 0.0 & & & & & 2 & 0.0 & 3 & 0.0 & & \\
\hline T. asahii & & & & & & & 1 & 0.0 & & & 1 & 0.0 & 1 & 0.0 \\
\hline T. inkin & & & & & & & & & & & 1 & 0.0 & & \\
\hline T. mucoides & & & & & & & & & & & 1 & 0.0 & & \\
\hline Other Trichosporon sp & & & & & & & 5 & 0.0 & & & 2 & 0.0 & 2 & 0.0 \\
\hline Rhodotorula spp. & & & & & & & 1 & 0.0 & 1 & 100.0 & 1 & 100.0 & & \\
\hline Saccharomyces spp. & & & & & & & 1 & 0.0 & & & 3 & 0.0 & & \\
\hline Pichia spp. & & & & & & & & & 1 & 0.0 & 6 & 0.0 & & \\
\hline Other yeasts & & & 1 & 0.0 & 5 & 0.0 & 4 & 0.0 & 36 & 0.0 & 105 & 0.0 & 56 & 0.0 \\
\hline Total & 373 & 0.3 & 657 & 0.5 & 1,054 & 0.9 & 844 & 0.1 & 673 & 1.6 & 1,126 & 0.4 & 793 & 0.3 \\
\hline
\end{tabular}

Includes all specimen types and all locations in the hospitals of 3 institutions.

Abbreviations: $\mathrm{R}$, resistant; spp., species; $C$. neoformans, Cryptococcus neoformans.

Table 5. Susceptibilities of yeast isolates to fluconazole and voriconazole by specimen type

\begin{tabular}{|c|c|c|c|c|c|}
\hline Specimen type & $N$ & Antifungal agent & $\% S$ & $\% S D D$ & $\% \mathrm{R}$ \\
\hline \multirow[t]{2}{*}{ Blood } & 663 & Fluconazole & 96.8 & 1.2 & 2.0 \\
\hline & 658 & Voriconazole & 97.9 & 0.5 & 1.7 \\
\hline \multirow[t]{2}{*}{ Urinary tract } & 1,027 & Fluconazole & 98.4 & 0.6 & 1.0 \\
\hline & 1,026 & Voriconazole & 99.0 & 0.4 & 0.6 \\
\hline \multirow[t]{2}{*}{ Lower respiratory tract } & 771 & Fluconazole & 99.5 & 0.4 & 0.1 \\
\hline & 762 & Voriconazole & 99.0 & 0.3 & 0.8 \\
\hline \multirow[t]{2}{*}{ Upper respiratory tract } & 194 & Fluconazole & 96.4 & 0.5 & 3.1 \\
\hline & 194 & Voriconazole & 98.5 & & 1.5 \\
\hline \multirow[t]{2}{*}{ Genital } & 103 & Fluconazole & 100.0 & & \\
\hline & 103 & Voriconazole & 100.0 & & \\
\hline \multirow[t]{2}{*}{ Skin/soft tissue } & 157 & Fluconazole & 99.4 & 0.6 & \\
\hline & 155 & Voriconazole & 100.0 & & \\
\hline \multirow[t]{2}{*}{ CSF } & 38 & Fluconazole & 97.4 & 2.6 & \\
\hline & 35 & Voriconazole & 94.3 & & 5.7 \\
\hline \multirow[t]{2}{*}{ Lower gastrointestinal tract } & 37 & Fluconazole & 86.5 & 5.4 & 8.1 \\
\hline & 36 & Voriconazole & 94.4 & 2.8 & 2.8 \\
\hline \multirow[t]{2}{*}{ Biliary tract } & 34 & Fluconazole & 100.0 & & \\
\hline & 34 & Voriconazole & 100.0 & & \\
\hline \multirow[t]{2}{*}{ Miscellaneous/others } & 2,397 & Fluconazole & 99.5 & 0.2 & 0.3 \\
\hline & 2,274 & Voriconazole & 99.8 & & 0.1 \\
\hline \multirow[t]{2}{*}{ Miscellaneous fluids } & 244 & Fluconazole & 99.6 & & 0.4 \\
\hline & 243 & Voriconazole & 99.2 & 0.8 & \\
\hline \multirow[t]{2}{*}{ Total } & 5,665 & Fluconazole & 98.8 & 0.5 & 0.7 \\
\hline & 5,520 & Voriconazole & 99.2 & 0.2 & 0.6 \\
\hline
\end{tabular}

Abbreviations: S, susceptible; SDD, susceptible dose dependent; R, resistant; CSF, cerebrospinal fluid. 
된 효모에서 칸디다 종의 분리 비율은 88.2-99.7\%로 변화가 큰 것으로 조사되었으며, 특히 2004년부터는 칸디다 종의 분리 비율이 줄고 칸디다 이외 효모의 분리가 증가하고 있음을 알 수 있었다. 즉 칸디다 이외의 효모가 전체의 $5.0 \%$ 에서 분리되어 ARTEMIS Program 전체의 결과(4.3\%)와 유사하였지만[8], ARTEMIS Program 전체의 결과에서는 1997년부터 2005년 까지 분리율의 변화가 없는데 비하여 국내 결과는 2005년부터 급격하게 칸디다 이외 효모의 분리율(2005년에서 2007년까지 평균 9.2\%)이 증가하고 있으며 분리되는 균종의 분포는 점차 다 양해지고 있다. 또한 국내의 동정되지 않은 칸디다 이외 효모의 비율도 2005년부터 크게 증가하여 ARTEMIS Program 전체 의 결과에 비하여 높았다. 이러한 차이를 보이는 원인으로 효모 가 분리된 검체 유형의 차이를 고려해 볼 수 있다. 즉 ARTEMIS Program 전체에서 효모가 분리된 검체 유형 중 요로, 생식기 및 기타 검체가 각각 $8.85 \%, 15.17 \%, 11.35 \%$ 인데 비하여[8] 국 내 검체 유형은 $18.13 \%, 1.82 \%, 42.31 \%$ 로 차이를 보이고 있어 (Table 5), 효모가 분리된 검체 분포가 각종 임상 검체에서 분리 된 효모에서 칸디다 종의 분리 비율에 영향을 주었을 것으로 생 각된다. 또한 국내에서 최근 5 년 사이에 칸디다 이외 효모를 단 순 오염균이 아닌 병원균으로 적극 분리하는 경향이 있음을 시 사한다고 볼 수 있다.

각종 임상 검체에서 분리된 칸디다 종의 균종 분포는 C. albicans가 가장 많아 ARTEMIS Program 전체의 결과와 동일하 였지만, C. albicans 분리 비율은 칸디다 종의 $86.4 \%$ (76.894.7\%)로 ARTEMIS Program 전체에서의 분리 비율인 $64.8 \%$ (61.4-70.9\%)보다 현저하게 높았다. 지금까지 보고된 국내 분 리 칸디다 종에서의 균종 분포는 크게 혈액과 혈액 이외의 검체 가 포함된 경우로 나누어 평가해 볼 수 있는데, 혈액에서 분리 된 균주만을 대상으로 한 경우 C. albicans가 25.9-49.0\% [1, $4,13,14]$ 를 차지하였으며, 혈액 이외의 검체가 포함된 경우 $C$. albicans는 51.4-90.6\% [2, 5, 6, 15-17]로 다양하게 보고되었 다. 특히 구강 내 칸디다 종에서 C. albicans는 $75.2 \%$ 와 $76.1 \%$ 로 보고된 바 있으며 $[15,16]$, 피부에서는 $90.6 \%$ 로 분리율이 높 았다[17]. 또한 2002년에서 2004년 사이에 국내에서 분리된 칸 디다 종에 관한 최근 연구에서 3 차 의료기관에서의 C. albicans 분리율이 3 차 의료기관이 아닌 병원에서보다 $10.8 \%$ 낮았다고 보고하기도 하였다[6]. 이와 같이 칸디다 균종 분포는 지역과 병 원에 따라서 다르고 연구에 포함된 검체 유형에 따라서도 다름 을 알 수 있다. 그러나 2000년대에 들어서면서 지속적으로 $C$. albicans 분리율은 감소하고 있고, 이와는 반대로 C. glabrata, C. tropicalis 및 C. parapsilosis와 같은 C. albicans 이외 칸
디다 균종의 분리는 증가하고 있는 추세임에는 틀림없다.

국내 분리 효모의 fluconazole과 voriconazole에 대한 내성 빈도는 대부분의 균종에서 ARTEMIS Program 전체의 결과보 다 낮은 빈도로 조사되었지만[8, 9], 일부 칸디다 이외의 효모에 서 높은 내성률을 보였다(Table 2). 즉, Trichosporon spp.와 Rhodotorula spp.에서 fluconazole 내성률이 더 높았고, $C$. neoformans와 Rhodotorula spp.에서 voriconazole 내성률 이 더 높았다. 이러한 결과가 비록 많은 균주에서 얻은 결과는 아니지만, 추후 이들 균종에 대한 보다 적극적이고 정확한 균종 동정과 fluconazole과 voriconazole에 대한 지속적인 내성률 조사가 필요할 것으로 생각되었다.

칸디다 종의 fluconazole과 voriconazole에 대한 내성 빈도 는 대부분의 균종에서 이전에 보고된 국내 분리 균주의 빈도와 $[1,3,5,6]$ 유사하게 나타나, C. glabrata, C. krusei 및 C. guilliermondii를 제외하고는 대부분 내성 빈도가 $1 \%$ 이하로 매우 드물었다. 한편 C. glabrata의 경우 2003년과 2007년에 voriconazole의 내성률이 fluconazole보다 높게 나타났는데, 이는 연구에 포함된 균주 수가 적어 그 원인을 분석할 수는 없 었지만, 지속적으로 관찰할 필요는 있을 것으로 생각되었다. 또 한 C. guilliermondii의 경우는 국내 분리 균주에서는 없었던[1, 6] fluconazole과 voriconazole에 대한 내성 균주가 1균주 $(5 \%)$ 검출되어 차이를 보였다. 이러한 차이는 연구에 포함된 균주수 가 적기 때문으로 생각되며, ARTEMIS Program 전체 결과에 서는 fluconazole과 voriconazole에 대한 C. guilliermondii 의 내성률이 각각 $10.7 \%$ 와 $5.2 \%$ 로 보고되었다[8]. ARTEMIS Program에서 임상에서 분리 빈도가 높은 C. albicans, C. glabrata 및 C. tropicalis의 fluconazole과 voriconazole 내 성률을 아시아, 유럽, 아프리카, 라틴 아메리카 및 북 아메리카 로 나누어 지역에 따라 분석한 자료에 의하면[8], C. albicans 의 내성률은 아프리카와 아시아가 $1 \%$ 이하로 낮았고 C. glabrata 의 경우도 아시아가 내성률이 가장 낮았으나, C. tropicalis는 특히 fluconazole에 대한 내성이 아시아에서 타 지역에 비하여 2 배 이상 높게 조사되었다[8]. 그러나 아직까지 본 연구에 포함 된 국내 분리 C. tropicalis에서는 내성률이 증가하는 경향을 보이지 않았다.

ARTEMIS Program은 신속하게 많은 자료를 수집하기 위하 여 참여한 각 병원 검사실에서 디스크확산법으로 항진균제 감 수성 검사를 시행하여 그 자료를 기준 검사실로 전송하였으며, 역학적 분류나 내성기전과 같은 추가적인 연구 수행을 위하여 무균 검체에서 분리된 균주를 수집한 연구이다. 참여한 각 기관 에서 전송한 감수성 결과에 대한 외부 정도관리와 ARTEMIS 
DISK 자료의 확인을 위하여, 2001년에서 2002년 사이에 수집 한 2,949 균주와 2005년에서 2007년 사이에 수집한 3,227 균 주를 대상으로 CLSI에 기준한 액체배지미량희석법과 디스크확 산법을 시행하여 참여 기관에서 시행한 디스크확산법 결과와 비교하였다[18, 19]. Fluconazole과 voriconazole에 대한 범주 내 일치율은 전체적으로 87-95.7\%로 우수하게 나타나 본 연구 가 유용한 자료로 사용할 수 있음을 보고한 바 있다[18, 19].

이상과 같이 ARTEMIS Program을 통한 장기간의 다국가 감시 연구에 참여한 본 연구는, 약 7년간의 장기간 동안 국내 각 종 임상 검체에서 분리된 효모의 균종 분포와 흔히 사용되고 있 는 azole계 항진균제인 fluconazole과 voriconazole 내성률을 확인해 볼 수 있는 의미 있는 자료라고 생각한다. 효모의 균종 분포와 항진균제 내성 양상이 지역과 병원, 검체 종류 및 사용 하는 검사법 등에 따라 다르게 나타날 수 있고, 분리된 검체를 중앙 검사실에 운송하여 검사를 시행할 경우의 검사 가능한 검 체수의 한계를 가질 수 있으므로, 간편하고 표준화된 진균 동정 법과 항진균제 감수성검사법을 확립하여 국내 다기관에서 시행 함으로 장기간의 많은 자료를 수집할 수 있는 대규모 국내 감시 연구가 필요할 것으로 생각된다.

\section{요 약}

배경 : 본 연구에서는 2001년부터 2007년까지 ARTEMIS DISK Global Antifungal Surveillance Program에 참여하여 얻은 결과를 이용하여, 국내 임상 검체에서 분리된 효모의 균종 분포와 fluconazole과 voriconazole에 대한 감수성 양상을 분 석하였다.

방법 : 국내 3 개 병원의 각종 임상검체에서 분리된 5,665 균 주의 효모에서 자료를 수집하였다. 감수성 검사는 CLSI M44$\mathrm{A}$ 에 근거하여 디스크확산법으로 시행하였다. 결과는 BIOMIC image analysis plate reader system (Giles Scientific, USA) 을 사용하여 판독하였다. 결과 분석을 위하여 균종명, 약제, 억 제대 지름, 카테고리에 의한 감수성 결과, 정도관리 결과 등을 전자 메일을 사용하여 전송하였다.

결과 : Candida albicans가 가장 흔히 분리되었으며, 최근 non-C. albicans 칸디다와 칸디다 이외 효모의 증가를 보이고 있다. 효모의 fluconazole과 voriconazole에 대한 감수성 결과 는 각각 $98.8 \%$ 와 $99.2 \%$ (감수성), $0.5 \%$ 와 $0.2 \%$ (약용량 의존 감수성), $0.7 \%$ 와 0.6\% (내성)였다. Candida krusei, Candida guilliermondii 및 Candida glabrata 3 균종의 칸디다에서 fluconazole 내성이 검출되어 fluconazole에 대한 감수성이 감
소한 것으로 조사되었다(<90\% 감수성). Fluconazole이나 voriconazole에 내성이 검출된 균종은 Cryptococcus neoformans, Trichosporon spp.와 Rhodotorula spp. 였다.

결론 : 효모의 균종 분포와 항진균제 감수성은 검체 종류, 사 용하는 검사법, 병원, 지역에 따라 다를 수 있기 때문에, 국내에 서 분리되는 효모의 균종 분포와 항진균제 감수성을 평가하기 위한 대규모의 장기간 감시 연구가 필요할 것으로 생각된다.

\section{감 사}

이 연구를 위한 ARTEMIS DISK Surveillance Program은 Pfizer에서 지원하였습니다.

\section{참고문헌}

1. Chae MJ, Shin JH, Cho D, Kee SJ, Kim SH, Shin MG, et al. Antifungal susceptibilities and distribution of Candida species recovered from blood cultures over an 8-yr period. Korean J Lab Med 2003; 23:329-35. (채명종, 신종희, 조덕, 기승정, 김수현, 신명근 등. 최근 8 년간 혈액에서 분리된 Candida 균종과 항진균제 감수성. 대한진단 검사의학회지 2003;23:329-35.)

2. Shin JH, Kim HR, Lee JN. Distribution and antifungal susceptibility of Candida species isolated from clinical specimens during the past six years. Korean J Clin Microbiol 2004;7:164-70. (신정환, 김혜 란, 이정녀. 최근 6년간 임상검체에서 분리된 칸디다의 균종 분포와 항진균제 감수성. 대한임상미생물학회지 2004;7:164-70.)

3. Lee MK, Kim HR, Kang JO, Kim MN, Kim EC, Kim JS, et al. Susceptibility and trailing growth of Candida albicans to fluconazole: results of a Korean multicentre study. Mycoses 2007;50:148-9.

4. Lee JS, Shin JH, Lee K, Kim MN, Shin BM, Uh Y, et al. Species distribution and susceptibility to azole antifungals of Candida bloodstream isolates from eight university hospitals in Korea. Yonsei Med J 2007;48:779-86.

5. Kim SH, Shin JH, Kim EC, Lee K, Kim MN, Lee WG, et al. The relationship between antifungal usage and antifungal susceptibility in clinical isolates of Candida: a multicenter Korean study. Med Mycol 2009;47:296-304.

6. Yoo JI, Choi CW, Lee KM, Kim YK, Kim TU, Kim EC, et al. National surveillance of antifungal susceptibility of Candida species in South Korean hospitals. Med Mycol 2009;47:554-8.

7. Pfaller MA, Diekema DJ, Rinaldi MG, Barnes R, Hu B, Veselov AV, 
et al. Results from the ARTEMIS DISK Global Antifungal Surveillance Study: a 6.5-yr analysis of susceptibilities of Candida and other yeast species to fluconazole and voriconazole by standardized disk diffusion testing. J Clin Microbiol 2005;43:5848-59.

8. Pfaller MA, Diekema DJ, Gibbs DL, Newell VA, Meis JF, Gould IM, et al. Results from the ARTEMIS DISK Global Antifungal Surveillance Study, 1997 to 2005: an 8.5-yr analysis of susceptibilities of Candida species and other yeast species to fluconazole and voriconazole determined by CLSI standardized disk diffusion testing. J Clin Microbiol 2007;45:1735-45.

9. Pfaller MA, Diekema DJ, Gibbs DL, Newell VA, Bijie H, Dzierzanowska D, et al. Results from the ARTEMIS DISK Global Antifungal Surveillance Study, 1997 to 2007: 10.5-yr analysis of susceptibilities of noncandidal yeast species to fluconazole and voriconazole determined by CLSI standardized disk diffusion testing. J Clin Microbiol 2009;47:117-23.

10. Isenberg HD. Clinical microbiology procedures handbook. 2nd ed. Washington, DC: ASM Press, 2003:3.11.2.

11. Sheehan DJ; National Committee for Clinical Laboratory Standards. Method for antifungal disk diffusion susceptibility testing of yeasts: approved guideline. M44-A. Wayne, PA: NCCLS, 2004.

12. Hazen KC, Baron EJ, Colombo AL, Girmenia C, Sanchez-Sousa A, del Palacio A, et al. Comparison of the susceptibilities of Candida spp. to fluconazole and voriconazole in a 4-yr global evaluation using disk diffusion. J Clin Microbiol 2003;41:5623-32.

13. Kang BK, Lee HJ, Suh JT. The Trends of the species and antimicrobial susceptibility of bacteria and fungi isolated from blood cultures (1986-1996). Korean J Clin Pathol 1998;18:57-64. (강병기, 이희 주, 서진태. 혈액에서 배양된 세균과 진균의 균종 및 항균제 감수성
의 추이 (1986-1996). 대한임상병리학회지 1998;18:57-64.)

14. Uh Y, Jang IH, Yoon KJ, Kim HY. Isolation trend and antifungal susceptibility of Candida species isolated from blood cultures. Korean J Infect Dis 2001;33:186-93. (어영, 장인호, 윤갑준, 김효열. 최근 혈액에서 분리되는 칸디다 균종의 분리추이와 항진균제 감수성. 감 염 2001;33:186-93.)

15. Kim YA, Cho DH, Lee K, Chong Y, Kwon HK. Yeasts isolated from oral cavity of the healthy adults. Korean J Clin Pathol 2000; 20:30-5. (김영아, 조동희, 이경원, 정윤섭, 권호근. 건강 성인의 구강 에서 분리되는 효모형 진균. 대한임상병리학회지 2000;20:30-5.)

16. Lee SH, Kim SW, Bang YJ. A study on the distribution of oral candidal isolates in diabetics. Korean J Med Mycol 2002;7:139-48. (이시 헌, 김상원, 방용준. 당뇨환자에서 구강내 칸디다균의 분포에 대한 조사. 대한의진균학회지 2002;7:139-48.)

17. Choi JH, Suh MK, Ha GY. Isolation and identification of Candida species in superficial cutaneous candidiasis. Korean J Dermatol 2002;40:1188-94. (최진혁, 서무규, 하경임. 표재성 피부칸디다증에서 칸디다 균종의 분리 및 동정. 대한피부과학회지 2002;40:1188-94.)

18. Pfaller MA, Hazen KC, Messer SA, Boyken L, Tendolkar S, Hollis $\mathrm{RJ}$, et al. Comparison of results of fluconazole disk diffusion testing for Candida species with results from a central reference laboratory in the ARTEMIS global antifungal surveillance program. J Clin Microbiol 2004;42:3607-12.

19. Pfaller MA, Boyken L, Hollis RJ, Kroeger J, Messer SA, Tendolkar $\mathrm{S}$, et al. Comparison of results of fluconazole and voriconazole disk diffusion testing for Candida spp. with results from a central reference laboratory in the ARTEMIS DISK Global Antifungal Surveillance Program. Diagn Microbiol Infect Dis 2009;65:27-34. 